\title{
LO QUE DIJERON LAS BRUJAS: JUÁREZ Y EL ESTRENO DE LA SINFONÍA- HIMNO DIOS SALVE A LA PATRIA
}

\author{
Ricardo Miranda \\ Conservatorio Nacional de Músical \\ Centro Nacional de Investigación, \\ Documentación e Investigación Musical
}

T o que dijeron las crónicas, no sólo de Dios salve a la patria, ـ sino del concierto verificado el primero de octubre de 1866 fue tan interesante como vasto pues se trató de una velada particularmente importante que contó con la significativa presencia del presidente Benito Juárez. El plato fuerte de la ocasión fue el estreno de Dio Salvi la Patria, una sinfonía-inno de Melesio Morales cuya música ofrece un interesante ejemplo a propósito de cómo pueden estudiarse una partitura y un concierto desde múltiples perspectivas y, por tanto, un caso de estudio ad boc que servirá para mostrar cómo ciertas cosas fueron -y suelen ser- escuchadas de manera superficial, mientras que otras, por su cariz técnico, requieren mayor detenimiento y cierto sentido técnico. Al mismo tiempo, se trata de una pieza emblemática estrenada en circunstancias extraordinarias y en un momento Fecha de recepción: 19 de agosto de 2019

Fecha de aceptación: 18 de septiembre de 2019 
de tensión política que todavía puede palparse, de un cambio de régimen y de una sociedad que tiene que realizar, inevitablemente, ajustes y compromisos. Todo ello permite realizar lecturas de diversa índole: políticas, sociales, estéticas, musicológicas e históricas.

El anunciado concierto había sido planeado para verificarse días antes, en coincidencia con las celebraciones patrias de septiembre. Los músicos integrantes de la Sociedad Filarmónica Mexicana así lo habían urdido, por razones más políticas que patrióticas y es por ello que cuesta creerle a Luis G. Ortiz, quien apuntó en su "Revista de la semana": "según saben ya nuestros lectores, el maestro Melesio Morales envió desde Florencia un himno para que fuese cantado aquí en las festividades de septiembre, y que ignoramos por qué razones no se verificó así. Su estreno tuvo lugar esta noche”. Y es que, si él sabía del envío de la partitura, la razón del estreno pospuesto también debió serle conocida: los miembros de la Sociedad Filarmónica habían buscado acercarse al gobierno restaurado y la tarea no les había sido fácil, pues iba precedida de su fama imperial, tanto como de las convicciones y creencias conservadoras de sus prominentes miembros. Nacida en pleno Segundo Imperio, la Sociedad Filarmónica había encontrado en la época de Maximiliano no sólo el momento propicio de su fundación y las mínimas condiciones para el establecimiento de su Conservatorio de Música, sino la protección directa e indirecta del emperador. Baste recordar que había sido la negativa de un empresario italiano para representar la Ildegonda de Morales lo que había detonado en 1866 la constitución de la sociedad y que, al conseguir la representación de la ópera, Maximiliano había ofrecido al quejumbroso empresario comprar las entradas que no se vendiesen.

La caída del Imperio había cogido a Morales con la mano en la puerta. Había salido de México en marzo de 1866 y su familia había quedado a cargo de un estipendio de la Sociedad Filarmónica: si para abril de 1867 la suerte de la Sociedad Filarmónica 
estaba en el aire, ni qué decir de la suya y la de sus parientes. Porque no sólo él sino varios miembros y benefactores de la Sociedad -entre ellos Aniceto Ortega y Tomás León- habían sido figuras destacadas en tiempos del Imperio; el cambio de régimen les caía como agua fría y la supervivencia de todos dependía, en gran medida, de un acercamiento al gobierno y de la adopción, pública al menos, de la bandera republicana. Como el más reconocido y el más afectado miembro de la sociedad eran uno y el mismo, Morales se puso a trabajar en la composición de una nueva pieza que firmó en Florencia en junio de 1867 y que habría de estrenarse el 16 de septiembre; una sinfoníahimno escrita para salvar a todos: a la patria, si acaso ésta tenía salvación, o al menos a los suyos y a la Sociedad Filarmónica. Al efecto aderezó la pieza con unos versos certamente escritos ¡en italiano! y puso en la obra una sección di battaglia donde las referencias musicales empleadas serían inmediatamente reconocidas por todos. La obra, además, fue el plato fuerte de un aparatoso concierto destinado a mostrar las bondades de la Sociedad y sus filarmónicos. Las dificultades propias de las obras, el curso incierto de los ensayos y la necesaria presencia de Juárez y su esposa hicieron que el concierto cambiara su fecha prevista, lo que explica el "decididamente” con el que El Constitucional anunció su definitiva celebración:

Mucho se habla del concierto que ha organizado la Sociedad Filarmónica Mexicana, y que decididamente tendrá lugar el martes 1o de octubre. Según los informes que hemos podido adquirir, parece que toman parte en esta gran solemnidad musical, más de trescientos cincuenta socios. Este solo número basta para indicar la importancia que ha adquirido aquella asociación. ${ }^{1}$

1 Anónimo, “Gran Concierto", El Monitor Republicano (27 sep. 1867). Otra de las gacetillas de El Monitor Republicano (14 sep. 1867) consignó: "En el ensayo de esta noche se estudiará el himno-sinfonía que compuso en Florencia 
Hay que traducir al español el extenso programa del concierto, no porque no lo hubiera estado, sino porque dejó por sentadas tantas cosas, y tuvo tal cantidad de erratas u omisiones, que más vale someterlo a los mínimos lineamientos actuales. Como fue reproducido en forma idéntica por distintos periódicos, ${ }^{2}$ cabe suponer que su redacción original salió del despacho de la propia Sociedad Filarmónica. Concebido como una verdadera muestra de proyectos y capacidades y forjado con olímpico desprecio por la resistencia del público, se trató de un programa, acaso irrepetible, en virtud de su duración, de su complejidad logística y del número desmedido de personas que en él participaron:

Segundo gran concierto vocal, instrumental y de orfeonismo de la Sociedad Filarmónica Mexicana, que tendrá lugar la noche del martes 1o de octubre de 1867.

Programa

Primera parte.

I. Obertura de la ópera Emma d'Antiochia, de Saverio Mercadante. II. M'è frullata nel pensier, coro de las brujas del primer acto de Macbeth, de Giuseppe Verdi.

III. Guai se ti sfugge un moto, Se ti tradisce un detto! terceto de Lucrecia Borgia, de Gaetano Donizetti.

IV. Fantaisie sur Un ballo in maschera, para violín y piano, opus 40, de Jean Delphin Alard.

V. Solo un alba, è vedremo la Croce..., Ah, vieni, è questo L'estremo addio!, dueto de Ildegonda, de Melesio Morales.

últimamente el Sr. D. Melesio Morales, y que se ejecutará solemnemente en el gran concierto que se está preparando y tendrá lugar a fines de este mes”. 2 Por ejemplo, El Constitucional (1ㅇ oct. 1867), p. 4 y El Monitor Republicano (28 sep. 1867), p. 3. 
VI. “Invocación vespertina” de Donizetti [¿O sacre polve, de L'Assedio di Calais?] ${ }^{3}$

VII. Obertura de Zampa, de Louis Joseph Ferdinand Hérold.

(para 10 pianos expresamente para este concierto)

VIII. Ainsi que la brise légère..., coro, escena y vals de Faust, de Charles Gounod.

Después de esta pieza, se bajará el telón, y volverá a alzarse de nuevo para la ejecución de la sinfonía-himno.

IX. Dios salve a la patria,

Que desde Florencia ha remitido el maestro mexicano Sr. D. Melesio Morales, encomendando su dirección al Sr. Agustín Balderas. Ocupará el órgano obligado el Sr. D. J. Francisco Contreras. Tomarán parte en esta pieza, la orquesta, bandas, las señoritas y señores socios aficionados, y los alumnos del Conservatorio.

Segunda parte.

X. Quipossa il bianco balsamo, coro de Ildegonda de Morales.

XI. Ah! fuggi da norte orribil cotanto, dueto de Poliuto, de Donizetti.

XII. Adagio y variaciones para dos flautas y piano sobre un tema de Semiramide de Gioachino Rossini

XIII. Bella figlia dell'amore, cuarteto de Rigoletto, de Verdi.

XIV. La caza del ciervo, de Laurent de Rillé.

XV. Marcha Zaragoza, de Aniceto Ortega.

XVI. Marcha Republicana, de Ortega.

Ejecutadas por la orquesta, una banda en 10 pianos a 40 manos que ocuparan varias señoritas y señores socios.

${ }^{3}$ De las obras consignadas por los periódicos ésta pudiera ser la única en duda, toda vez que el catálogo de Gaetano Donizetti no registra una Invocación vespertina como tal. Mi apuesta es que se trató de la escena final del segundo acto de L'Assedio di Calais por razones que describo más adelante. 
XVII. Saint bienheureux..., Courons à la vengeance!, plegaria y gran coro del mercado de La Muette de Portici, de Daniel-François Auber.

Ópera y música instrumental; coros y diez pianos a cuarenta manos; una pieza que requería cierto montaje escénico y una banda de guerra en la escena: ante semejante despliegue de fuerzas filarmónicas no sorprende que el concierto haya tenido que posponerse. Pero antes de pasar a la lectura y audición del programa, habrá que recuperar más voces que escribieron acerca del concierto en la prensa. Alfredo Chavero, por ejemplo, hizo una muy buena semblanza del momento y circunstancia en el que aquella presentación tenía lugar:

Ayer apenas se escuchaba el trueno del cañón sitiador; ayer apenas vagaban por las calles las mujeres pálidas de hambre; ayer apenas pasaba sobre la hermosa México la mano de hierro del despotismo y la traición, y hoy como luce el sol más brillante sobre las rosas empapadas de rocío, después de la tormenta, así se ha escuchado más dulce y más cadencioso el canto de los niños.

La Sociedad Filarmónica es un prodigio. No ha nacido apadrinada por ningún gobierno; ha brotado como una flor en el desierto, en medio de nuestras desgracias políticas; y al gemido de la patria ha contestado con sus armonías, como diciéndole: esperanza. ${ }^{4}$

Por su parte, Luis G. Ortiz describió algo de la decoración del escenario:

El foro representaba un magnífico salón adornado con grandes candelabros y trofeos nacionales; al fondo se descubría un delicioso jardín, y todo el centro de la escena se veía completamente

${ }^{4}$ Alfredo Chavero, "Editorial. La Sociedad Filarmónica”, El Siglo Diez y Nueve (2 oct. 1867), p. 1. 
lleno de los numerosos miembros de la Sociedad Filarmónica, de ambos sexos y de todas edades. El golpe de vista era soberbio $\mathrm{y}$ todo arreglado con el tino e inteligencia que distingue a tan notable plantel. ${ }^{5}$

Como el mismo Alfredo Bablot apuntó, también desde las páginas de El Monitor, eran tantas las piezas y tantos los detalles de tan pródigo concierto, que faltarían cuartillas si alguien quisiera dar cuenta pormenorizada de todo. Se trata de un buen consejo, así que antes de abordar la pieza de Morales, y de contemplar con mayor detalle ciertas partes del programa a la luz de las circunstancias políticas, valga mencionar, al menos, algunos aspectos relevantes de lo escuchado aquella larga noche. Uno, que ha sido reseñado reiteradas veces, fue el estreno de las dos marchas encomendadas a Aniceto Ortega: la Zaragoza y la Republicana. La Sociedad presentó aquellas marchas convencida de que no tenía la nación un himno que la representase: repudiaban el compuesto por Nunó en tiempos de Santa Anna $\mathrm{y}$ ofrecían al respetable la elección de un fragmento que fuese un nuevo canto patrio. De acuerdo a Bablot, la gente hablaba y discutía sobre ello al salir del teatro, aunque, como apuntó Chavero, si "en la magnífica marcha del Sr. Ortega nos han llenado las armonías; nos ha seducido más el recuerdo que en ellas se encierra de nuestro inmortal Zaragoza". Algo semejante pensaron los diletantes atrapados por Bablot:

Las marchas del Sr. Don Aniceto Ortega son dos inspiraciones felicísimas; el ritmo marcial está perfectamente marcado, el canto es fácil y sencillo, tiene fluidez la melodía, está bien definido y homogéneo el pensamiento y su hilación es franca y natural; los aplausos del público demostraron preferencia por la Marcha Zaragoza. Esta

${ }^{5}$ Luis G. Ortiz [atrib.], "Revista de la semana”, El Siglo Diez y Nueve (6 oct. 1867), p. 1. 
es de hoy más la marcha nacional mexicana. Así lo ha decidido y sancionado el voto popular que ojalá tenga tan buen acierto en sus sufragios políticos. Empero, al concluir la función había diversidad de opiniones sobre ambas composiciones; unos se inclinaban a la marcha Zaragoza, otros a la Republicana. Pudimos oír, a la salida del teatro, algunos fragmentos de una conversación, que define y resume la discusión, entre un profano y un inteligente:

-Yo prefiero la Republicana, decía éste, porque hay en ella ideas felices, gran ciencia, buenas resoluciones armónicas y modulaciones ricas, nuevas y originales, que revelan conocimientos profundos a la par que fuego sacro.

El profano no podía explicar la razón de su preferencia por la marcha Zaragoza y apelaba al nec plus ultra del raciocinio: hacía como aquel amante de la comedia clásica, que daba a su amada esta explicación sublime:

-Te amo porque... ¡Porque te amo!

El otro número que nadie dejó de comentar fue la interpretación al violín de aquella fantasía sobre temas de Verdi de Alard. Su ejecución estuvo a cargo del joven violinista de 11 años Jacinto Osorno y lo más fácil de afirmar, y lo más reiterado al escribir, fue que se trataba de un nuevo Paganini, un Paganini mexicano que era la muestra fehaciente del futuro brillante que ya despuntaba para la patria.

La Sociedad Filarmónica y sus miembros tenían todo a su favor al poder mostrar el abanico de sus posibilidades. En este sentido, hay que destacar también la participación del Orfeón del Águila Nacional dirigido por Julio Ituarte. Se trata de una de las tareas sociales más relevantes que implementó la Sociedad, que seguía en ello la tradición europea entonces en boga. Ya desde la Viena de Schubert, habían proliferado los Männerchor, y en Francia esa tradición había sido impulsada -precisamente- por Laurent de Rillé, cuya Caza del ciervo interpretaría el orfeón mexicano. Acerca de todo esto, Bablot escribió: 
La primera asociación coral que se ha instituido en México ha nacido en el seno de la Sociedad Filarmónica, merced a la iniciativa del prosecretario de ella, el Sr. D. Luis F. Muñoz Ledo, y del joven pianista Sr. D. Julio Ituarte. La Sección de orfeonismo les hace mucho honor, pues a los seis meses, a lo sumo, de estudios ejecutan sus miembros las más difíciles piezas de coros sin acompañamiento con una perfección que sólo adquieren las sociedades corales de Europa después de años enteros de trabajos constantes, lo que es una nueva prueba de la aptitud de los mexicanos para la música. Cantaron con una precisión admirable, con una afinación intachable, y con expresión delicadísima, una preghiera de Donizetti y un trozo cinegético de música vocal imitativa de Lorenzo de Rillé. 6

El mensaje lanzado por la sección de orfeonismo era tan viejo como claro: la música puede desempeñar, además de todo, un papel aglutinante; ser un poderoso factor de cohesión social. Esos coros acercaban la música al amplio público y tenían un potencial social enorme, insospechado. Y aunque hoy en día nos parezca muy cuestionable que sólo fuesen agrupaciones masculinas, no se nos olvide que corrían otros tiempos. De hecho, el mismo Bablot había comenzado su crónica del gran concierto halagando primero que a nadie, a las mujeres, quienes venciendo prejuicios propios y ajenos, se habían plantado en el escenario:

No se podía menos que experimentar una honda emoción cuando al alzarse el telón se vio poner en pie, en señal de salutación digna y deferente, a esa multitud de jóvenes y modestas aficionadas que habían vencido su púdica timidez para afrontar el peligro y sobreponerse

\footnotetext{
${ }^{6}$ Alfredo Bablot, "Gran concierto público de la Sociedad Filarmónica Mexicana”, El Monitor Republicano (4 oct. 1867), p. 1.
} 
a la preocupación de la escena pública a fin de cooperar a una obra de beneficencia y de caridad $[\ldots]{ }^{7}$

Un renovado papel de las mujeres educadas musicalmente, una sociedad que encontraría en los orfeones un modelo ideal de convivencia social, una educación musical gratuita que serviría para enaltecer a la patria en tantos aspectos, el cuidado y educación de los niños quienes por medio de la música encontrarían un cauce para su potencial... tales eran las cartas que la Sociedad Filarmónica ponía sobre la mesa. No sorprende así que Alfredo Chavero haya encontrado, por encima de lo estrictamente musical, razones cívicas para enaltecer aquel concierto y a la Sociedad que le había organizado:

Sí; repetiremos que en el concierto de anoche hemos visto más que una diversión, más que un público ocurriendo en masa a llenar un teatro y a llevar su óbolo para sostener la sociedad filantrópica de que nos hemos ocupado; hemos visto también una prenda de seguridad para el porvenir, una promesa de paz, y una revelación de la grandeza de nuestra patria.

[...] Así México puede decir: [...] He tenido sitios heroicos como los de Troya. He arrancado coronas y he tomado ciudades. $\mathrm{Y}$ en medio de estas ocupaciones he encontrado tiempo para mis placeres, y después del clarín del combate, han entonado los niños sus plegarias. ${ }^{8}$

Desde luego, las crónicas del concierto dieron amplia cuenta del plato fuerte del programa. Como tales reseñas serán un estupendo contrapunto para poder hablar de esa pieza tan particular e interesante, habrán de sonar en los párrafos siguientes.

7 Alfredo Bablot, "Gran concierto público de la Sociedad Filarmónica Mexicana”, El Monitor Republicano (4 oct. 1867), p. 1.

${ }^{8}$ Alfredo Chavero, "Editorial. La Sociedad Filarmónica", El Siglo Diez y Nueve (2 oct. 1867), p. 1. 
Lo que las crónicas dijeron de la música de Morales fue poco pero muy halagador. "Nosotros", adivirtió Luis G. Ortiz a sus lectores:

[...] con nuestra grande afición, a falta de ciencia, no os podremos decir que tal trozo comenzó felizmente por una melodía larga y expresiva en la menor; que después modula a la tercera mayor y vuelve al tono por una cadencia cortada sobre la sexta aumentada, trayéndonos a la fórmula de la dominante cuya solución es el tono primitivo. Esta es una tecnología difícil de entender, cuyo sentido ignoramos y que sólo se debe usar allá al seno de las grandes academias. ${ }^{9}$

No sé si admirar o amonestar la condena a esa "tecnología difícil de entender" que Ortiz rechazó en favor de un recuento menos técnico y más generalizado. La culpa, después de todo, quizá la tengamos los propios músicos al encontrar ineludible utilizar, en ocasiones, una jerga que sólo comprenden algunos y que, además, suele caer seguido en el escollo tautológico: decir que una pieza en modo menor "modula a la tercera mayor", alcanza su dominante y nos lleva de vuelta "al tono primitivo" es más bien una cáustica burla de quienes se las dan de entendidos: semeja decir algo complicado y, en realidad, sólo reitera una obviedad.

Y sin embargo... La partitura de Dio Salvi la Patria resulta particularmente interesante desde el punto de vista técnico. Lo hace no sólo en virtud de ser un híbrido sensacional (sinfoníahimno) sino por tantas particularidades que despliega. ${ }^{10}$ Así que

${ }_{9}$ Luis G. Ortiz [atrib.], "Revista de la semana”, El Siglo Diez y Nueve (6 oct. 1867), p. 1.

10 Gómez Rivas, “El pasaporte musical del Conservatorio...”, p. 60, fue el primero en ofrecer una descripción más detallada de esta importante partitura. 
vayan dos párrafos de “tecnología difícil de entender”, y nuestra disculpa por ello a don Luis Gonzaga Ortiz.

Lo que dice la carátula de la partitura de la sinfonía-himno lo dice en italiano:

\section{All'Egregio Signore}

Ramón Terreros

\section{¡Dio Salvi la Patria!}

Sinfonia=Inno

(A tutti Orchestra, cori, Organo (o armonium) e Fanfara)

Da eseguirsi nel Gran teatro Nazionale

Del

Messico

l'anno 1867

Musica del

Mtro. Melesio Morales ${ }^{11}$

Cada una de las dos grandes partes de la partitura ofrece rasgos técnicos y estructurales muy interesantes. La sinfonía, para empezar, puede subdividirse en tres grandes secciones: la primera, a modo de obertura italiana, consta de dos temas en do menor y un conspicuo tema que previsiblemente "modula a la tercera mayor", es decir a mi bemol mayor, y que no es sino La Marseilleise. La evocación del himno francés, acompañado de sus respectivos redobles de tambor, es interrumpida por un toque militar y se escuchan enseguida los ecos de otras conocidas piezas, también en mi bemol mayor. Al escribir acerca de esta partitura, Karl Bellinghausen anotó que la obra "utilizaba el tema de La Marsellesa como símbolo de la libertad, así como el de la canción republicana Los cangrejos, que se

11 Según el manuscrito y partes de la obra. 
burlaba de los reaccionarios pro imperialistas". ${ }^{12}$ Es una pena que Bellinghausen no nos haya dicho en qué compás escuchó Los cangrejos, aunque supongo que se refiere al mismo pasaje que a continuación nos ocupa; en todo caso, los que si se escuchan-burlones, festivos, confiados-son los archiconocidos ecos de Mamá Carlota:

\section{Ejemplo 1}
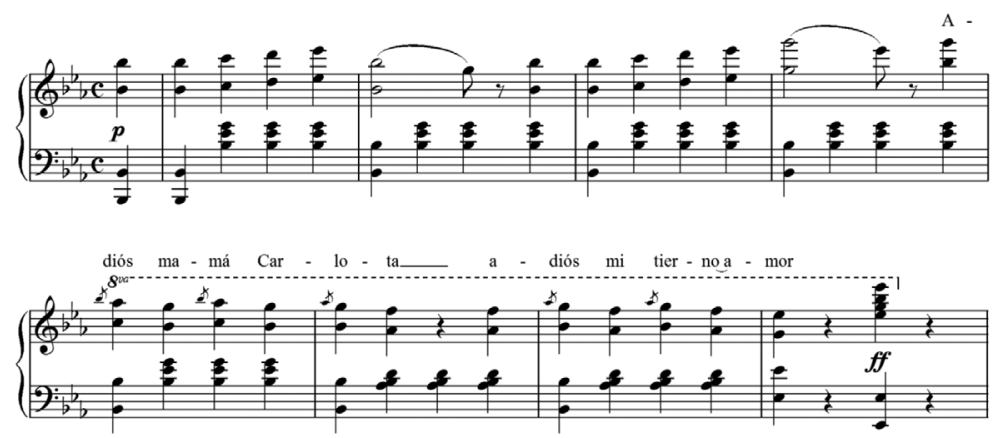

Dio salvi la Patria (fragmento, reducción para piano de Julio Ituarte, con letra añadida.)

Tampoco es cierto que La Marseilleise sea empleada por Morales como un "símbolo de libertad", o que Mamá Carlota sea una burla. Esos temas son escuchados como proemio de lo que sucederá en la última parte de la sinfonía, que fue escrita en modo di battaglia. Siguiendo al Beethoven de La Victoria de Wellington, Morales quiso citar los himnos de ambos bandos, antes de enfrentarlos en una guerra orquestal. Pero recuérdese que Morales daba por sentado que México no tenía para octubre de 1867 un himno nacional y que lo escrito por Nunó -por malo, por espurio- le merecía un desprecio que no se privó de

12 Bellinghausen, “Esbozo biográfico de Melesio Morales”, p. xxix. 
compartirnos. ${ }^{13}$ Así que la reminiscencia de algunas canciones populares, que todos conocían y reconocían, bastaba para dar a entender quiénes eran los contrincantes.

No deja de ser interesante que la primera parte de la sinfonía esté escrita a la usanza de las oberturas de ópera italiana; no desarrolla ninguno de sus temas, sino que los temas referidos se tocan dos veces, tal y como Rossini habría hecho en cualquiera de sus apuradas oberturas. Y tal y como Rossini habría hecho en cualquiera de sus escenas, la segunda parte de la sinfonía de Morales es, propiamente, una cavatina; un pasaje de indudable raigambre operática, que despliega una de aquellas melodie lunghe, lunghe, lunghe (Verdi dixit) que Bellini hizo famosas y que tanto gustaron a Chopin. Pero en un gesto atípico en él, que muchos celebraron, Morales no pensó en alguna cantante, sino que encomendó el largo y bello pasaje al oboe solista. Con ello no sólo Morales no perdía las cualidades intrínsecas del canto, sino que se permitía un simbólico gesto. El oboísta en turno fue nadie menos que Feliciano Chavarría, quien antes de salvar a la patria desde los atriles de la orquesta de la Sociedad Filarmónica, ya la había salvado durante el sitio de Querétaro, distinguiéndose en el verdadero campo de batalla. De hecho, como contó Antonio G. Pérez, también al músicosoldado -como a Morales in absentia, como a Ortega, como a quienes dirigieron las demás obras- se le entregó aquel día una corona en reconocimiento:

Uno de los hechos conmovedores que tuvieron lugar en la fiesta de que nos ocupamos, fue el que hubiera recibido una corona de artista el C. general Feliciano Chavarría, quien después de haber servido

${ }^{13} \mathrm{Al}$ respecto, puede leerse su irreverente artículo "El Himno Nacional y la Marcha Zaragoza: Don Jaime Nunó”, en Morales, Laborperiodística, p. 110 y ss. De la música del canto patrio Morales opinó: "Como obra de arte, se entiende que no vale un tamal...". 
a su patria en los campos de batalla, ha vuelto a ejercitar el divino arte de la música. ${ }^{14}$

A los ojos de la Sociedad Filarmónica y sus miembros, Chavarría era el ciudadano ejemplar. Bablot lo llamó “Cincinato musical” y Gabino F. Bustamante le dedicó un bello párrafo que habla, por consecuencia, de la música de esta cavatina:

En esta sinfonía-himno que desde Florencia remitió el distinguido maestro cuanto patriota mexicano Melesio Morales para solemnizar el triunfo de la República, en esa composición llena de bellezas, ha hecho sobresalir una, que no podemos dejar desapercibida. Acordándose en los momentos en que lo escribía, de su hábil compañero y amigo el general republicano Feliciano Chavarría, le ha escrito un solo de oboe en el que pudiera sobresalir dignamente como artista, el que tanto se había distinguido en la campaña como soldado del pueblo. No sabemos con qué hemos gozado más, si con el deleite que nos producían las sentidas y bien expresadas notas del oboe, o con el paralelo que mentalmente estábamos formando entre el hombre que hoy empuñaba ese instrumento y el que hace dos meses apenas que empuñaba la espada. No podíamos convencernos de que era el mismo el que se distinguía en el sitio de Querétaro al frente de sus tropas el que hoy sobresalía en medio de una orquesta. ¡He aquí un tipo digno de imitarse por todos los soldados; un general de la república convertido de la noche a la mañana en un simple miembro de una banda de músicos! ¡Qué orgullosa debe estar la Sociedad Filarmónica con socios de esta clase! ¡Qué grande debe ser el porvenir de nuestra patria si cuenta con muchos hijos que posean esa abnegación y ese patriotismo! ${ }^{15}$

${ }^{14}$ Antonio G. Pérez, "El concierto de anoche", El Siglo Diez y Nueve (2 oct. 1867), p. 3.

15 Gabino F. Bustamante, “Editorial. La música.”, El Monitor Republicano (2 oct. 1867), p. 1. 
Este pasaje nos ofrece un ejemplo perfecto de cómo la historia puede cambiar nuestra audición: escuchada sin estos antecedentes, la cavatina y su escritura semejan una de tantas que inundaron las óperas italianas del siglo xIx; pero esas mismas notas cobran otro sentido al conocerse el conmovedor trasfondo biográfico del intérprete para quien fueron concebidas:

\section{Ejemplo 2}
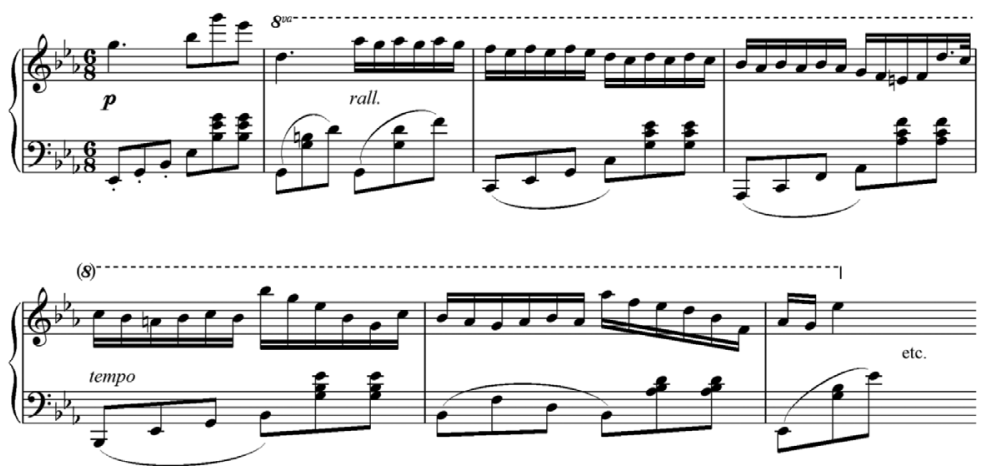

Dio salvi la Patria (fragmento, reducción para piano de Julio Ituarte).

Huelga decir que la cavatina del oboísta-general no renunció a incluir su cadenza, donde las virtudes técnicas del intérprete pudieron desplegarse para gusto y admiración de los presentes. $\mathrm{Y}$ al terminar su florido canto la partitura introduce un tempo di mezzo, un nuevo tema lento cuya escritura homófona en los alientos y metales presagia un momento solemne, adusto. Compases adelante vuelven a sonar las notas de La Marseillaise, efímeras, lejanas, y un golpe de tambor, en efectiva representación del primer cañonazo, desata la tormenta. La Battaglia, tercera parte de la sinfonía, recurre en su escritura a un carácter agitado, que realiza intensas variantes armónicas sobre un incesante trémolo en las cuerdas. Las horrísonas disonancias en la parte 
grave contribuyen con efectividad a transmitir la inestabilidad y teatralidad propias para este pasaje que, en sus oleadas de escalas encomendadas a los alientos, y en el incesante batir de sus tambores de guerra (Morales pidió en la partitura 16 tamborileros en la escena) parecen seguir de cerca al Beethoven de La batalla de Vitoria. Morales, sin embargo, no alargó la trifulca, sino que, tras expresar la intensidad de su fragor, hizo desembocar su música en los acordes iniciales del Inno.

Dice la partitura original que los versos cantados fueron "poesia di Stefano Fioratti (scritta espresamente)". Y aunque uno suponga que Dios, por serlo, comprenderá cualquier idioma en el que se le implore, a Morales le pareció toda su vida que no había por qué escribir en otra lengua que no fuera la de su amada Italia. Así que, sin más preámbulo, aunque con el añadido de una "fanfara sulla scena" (es decir, una banda militar que se une a las fuerzas orquestales), se escuchan los siguientes versos:

\section{Ejemplo 3}
Al ferreo strepito
Deb! Salva il misero
Di bronzi e d'armi
Mio suol natio
Lieti succedano
Della mia patria
Soavi carmi
O Dio pieta. ${ }^{16}$

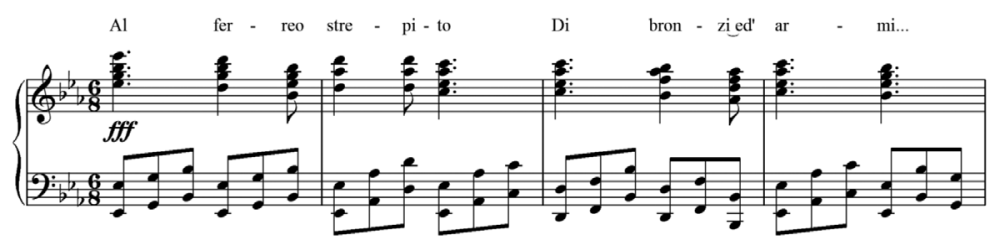

Dio salvi la patria (fragmento, reducción para piano de Julio Ituarte, con letra añadida).

16 Al férreo clamor / De los bronces y armas /alegres sucedan /cánticos suaves. ¡Ah! Salva al pobre /

Mi terruño natal / De mi patria / Oh Dios, ten piedad. 
Antes de pasar al canto de la tercera estrofa del himno, tiene lugar la parte más impactante de la obra, un preghiera dei fanciulli, donde 16 niños-siempre según la partitura- le piden a la Virgen por la salvación de la patria. En las indicaciones escénicas de su manuscrito, Morales anotó: "I ragazzi inginocchiandosi col più santo fervore", y en efecto, los niños de la Sociedad Filarmónica se hincaron para cantar. Los cronistas coincidieron en que aquel momento era fulgurante, el toque maestro de la obra y el más estrujante de cuanta música se escuchó en aquella memorable sesión. ¿ Así lo habrá entendido Juárez? Con fino sentido dramático, como corresponde a un compositor de óperas, Morales hizo que los niños cantasen sus piadosas líneas al religioso acompañamiento de un órgano obligatto:

\section{Ejemplo 4}

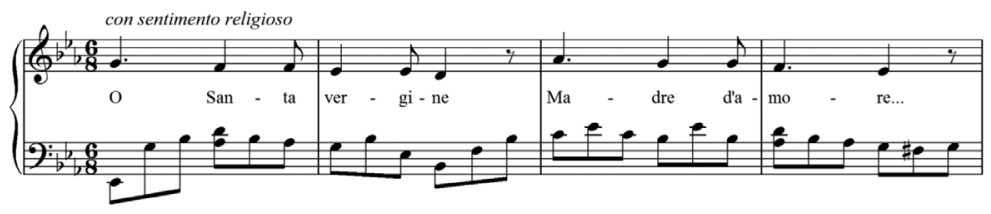

Dio salvi la patria: preghiera dei fanciulli (reducción para piano de Julio Ituarte, con letra añadida).

"La invocación Dios salve a la patria", anotó Bablot en su columna:

Es un grito del alma y las voces argentinas de los niños arrodillados que ruegan al cielo por la felicidad del suelo natal, ha bañado en lágrimas el rostro de casi todas las señoras que asistieron al concierto de antenoche, así como también los de muchos que, llamándose fuertes para disimular la fealdad de su sexo, se impresionan profundamente a impulsos de los sentimientos nobles, generosos y elevados. Los niños cantaron con fervor y 
expresión, porque al aprender la música del himno aprendieron a amar a su patria. ${ }^{17}$

La preghiera dei fanciulli termina con el ritornello del himno que está vez será cantado en forma apoteósica, incluida su tercera estrofa:

\section{Non piú d'estraneri \\ Venduta schiera \\ La nostra insanguini \\ Santa bandiera. ${ }^{18}$}

La singular estructura de la sinfonía-himno y los numerosos detalles de su partitura bastan para leer la pieza como una de las más interesantes del repertorio orquestal del siglo xIX mexicano, y no es ocioso recordar que a Morales le encantaron este tipo de composiciones, como se aprecia al escuchar su hoy más conocida Sinfonía-Vapor, dedicada a los caminos de fierro e idealmente acompañada -faltaba más- por los sonidos de una locomotora real. Pero de regreso a la partitura de la sinfonía-himno, y aunque don Luis Gonzaga Ortiz nos quiera retirar el habla, el previsible trayecto tonal de la pieza no es asunto menor: ese viaje tonal del do menor inicial al apoteósico mi bemol mayor que culmina la pieza, es un trayecto armónico previsible, y por ello lógico y adecuado para transmitir el ánimo del triunfo y la esperanza finales. Es un trayecto tonal más convencional que el fijado por Beethoven en sus siegessymphonien -en Egmont, en las sinfonías quinta o novena y, por supuesto, en La victoria de Wellington- pero, como hemos visto, Morales era un músico y una persona de miras conservadoras y mucho más a gusto en

17 Alfredo Bablot, "Gran concierto público de la Sociedad Filarmónica Mexicana”, El Monitor Republicano (4 oct. 1867), p. 1.

18 Nunca más a las extranjeras / legiones vendidas / nuestra ensangrentada / santa bandera. 
el mediterráneo de los teatros de ópera que entre los bosques germanos. En todo caso, esa trayectoria tonal es finamente construida pues el mi bemol que anunció originalmente $\mathrm{La}$ Marsellesa se transfigura a lo largo de la obra; ya en la cavatina para oboe, ya en el himno final. Y es que, para salvar a la patria, lo primero que se necesita es un trayecto armónico adecuado. Y tal vez alguna cosa más. Ópera, por ejemplo.

Lo que dijo José Tomás de Cuéllar de aquel concierto nos rescata de las pautas inexpugnables para llevarnos al sabroso terreno del observador costumbrista. Su préambulo es largo, pero no tiene desperdicio:

Espléndido estuvo el concierto; como lo habíamos anunciado, fue uno de los espectáculos más brillantes que ha habido en el hermoso Teatro Nacional. La concurrencia fue numerosísima, al grado de faltar localidades para las personas que no se anticiparon a sacar sus boletos.

Reinaba la animación y la alegría, en primer lugar porque no había franceses, cuyos uniformes matizaban en otro tiempo las reuniones con manchas de sangre; en el teatro anoche no había más que mexicanos, y llamaban la atención uno que otro oficial mexicano con uniforme. Las señoras se disputaban la palma en atractivo y galas; eran en los palcos guirnaldas de gasas, flores, perlas brillantes, blondas y plumas, dejando ver sonrisas, semblantes hechiceros, manos pequeñas y pechos de alabastro. Merecidas guirnaldas animadas para coronar el genio y el talento.

En las lunetas, el sexo feo se extasiaba en mayoría, pero como a manera de tábanos zumbaban por aquí y por allá algunos pollos, de esos que han brotado últimamente como langosta, como palomitas de San Juan; pollos del género miope, ignorantes los más, empalagositos los unos, insustanciales otros, estirados todos, trigueñitos 
aquellos, de pelo enmarañado otros: estos pollos, en cuyos oídos suena como ruido del otro mundo el cacareo de las gallinas, están en la edad de creer que ellos son los que les gustan a ellas, y no viceversa, de manera que la música anoche para los pollos, era verdadera música celestial, quiere decir, que no la entendían. ¡Qué habían de entender! Si allí estaba Lola y Concha, y Luisa y Juanita, y aquella del bonito pie, y la otra del peinado rojo, y Josefina y Anita, y todas, todas, y a cuál más lindas: en resumen, los pollos estaban aturdidos porque tenían la música por dentro.

¡Lástima! Si hubieran sido menos los zumbadores, aquel ramillete hubiera sido como de los de los maestros en este género de obras de arte: los pintores de flores, generalmente no terminan su ramillete, sino colocando sobre las hojas algunos insectos; esto, sobre ser conforme a la naturaleza, puesto que esos insectos viven entre las flores, le da a la obra la armonía del contraste y la verdad del natural, pero son uno que otro: anoche eran muchos los insectos, al grado de tapar algunas hojas del ramillete. ${ }^{19}$

No sabía Don Facundo que los pollos que escuchan música celestial habían llegado a los conciertos para quedarse y que lo que describe su inmejorable reseña es, a todas luces, el comportamiento habitual del respetable de cualquier teatro de ópera; de su época, o de ésta. Pero tras revelarnos algo sobre la concurrencia vino a continuación su resumen, no tanto del concierto cuanto del patriotismo declarado de la Sociedad Filarmónica:

En cuanto a la ejecución de las magníficas piezas ¿qué diremos? Por más que tengamos el honor de pertenecer a la Sociedad Filarmónica, no expondremos nuestra reputación en la calificación aventurada de un semitono ni de un compás: ¡paso a los maestros! Y nosotros plegamos nuestras banderas. Nosotros estuvimos encantados,

19 Facundo [José T. de Cuéllar], "Variedades. El concierto de anoche”, El Correo de México (2 oct. 1867), p. 2. 
porque sin dejar de contemplar a ratos a las bellas en justo tributo a la galantería, había una cosa que nos hacía entregarnos a las más hondas cuanto más halagadoras reflexiones: un pueblo que recobra su gloria y sus derechos, un pueblo que triunfa de la tiranía del extranjero, y que se estrecha en una noche para cantar sus glorias. Artistas de corazón, de genio, y patriotas, que enseñan la música a las niñas y con las notas inculcan el amor por esta patria desgraciada. Señoritas mexicanas cuya esmerada educación las lleva al templo del arte, y cuyo amor al arte las hace pisar el escenario sin ambición mezquina, sino por filantropía y patriotismo; una sociedad filarmónica, en fin, que ofrece a México un espectáculo encantador, presentando una falange de artistas mexicanos, y trescientos discípulos, niñas pobres que tendrán un porvenir, y serán tal vez la honra de México recorriendo el mundo como la Peralta; un público que no paga sueldos ni despilfarra, sino que da la educación a la juventud, y nos deleita a costa de sus sacrificios personales.

Bien se ve que lo que acaso Juárez no entendió aquella prolongada noche, los cronistas de la prensa se encargaron de ponérselo por escrito. La Sociedad Filarmónica quiso mostrarse, quiso colocarse a los ojos del gobierno como un agente benéfico, que estaba y había estado por encima de las turbulencias políticas. Su cuestionable pasaporte imperial no habría de ser obstáculo para que la restaurada república no le brindase apoyo, y si las notas de tanta música no bastaban para dejarlo en claro, Gabino F. Bustamante, Tomás de Cuéllar y Alfredo Bablot se cuidaron de consignarlo en sus reseñas. Pero fue el autor de la Ensalada de pollos quien se llevó las palmas en la parte final de su irrepetible y claridosa columna:

Y por último, un gobierno que va, que ve, que oye, que dice bien y que no dice: toma.

Nosotros, si fuéramos gobierno (que Dios nos libre), diríamos: -iQué hermoso estuvo el concierto... pero esto se puede decir sin 
ser gobierno... Entonces preguntaríamos: ¿Con qué fondos cuenta esa Sociedad Filarmónica? También esta pregunta se puede hacer sin ser gobierno.

Pues diríamos: ¡esta Sociedad debe tener muchos gastos! ¿Y qué? La observación sería buena, pero puede hacerla cualquier pelagatos.

¿Pues qué, por fin, diríamos si fuéramos gobierno?... Ya se ve que es dificilillo decir algo en tal predicamento; nos declaramos ineptos para tan alto puesto, porque ni aun en el terreno de la suposición podríamos dar palotada; pero porque no se crea que nos andamos por las ramas y recordando a Sancho Panza, allá va esa y salga lo que saliere, pues al fin nos hemos propuesto fingir por un momento que gobernamos.

Señores fundadores y mantenedores, profesores (aunque saliera con muchos ores) de la Sociedad Filarmónica Mexicana: yo, presidente de la república ya hace diez años, con otros cuatro en lontananza, si acaso, complacido y satisfecho con vuestros adelantos y patriotismo... Aquí haría yo que mi Ministro de Relaciones me redactara un considerando muy elocuente, después del cual diría yo aquello de be venido en decretar (que es una frase muy bonita) y decretaba:

Primero. Regalarle a la Sociedad un edificio bueno de esos que se confiscan luego, y que andan hoy con que si lo compro o no lo compro, y si pago o no pago, y todas esas cosas.

Segundo. Le daría yo algo de mosca en efectivo, para que la pobrecita Sociedad pagara algunos picos, porque ahí donde la ven ustedes, tan fastuosa y tan elegante, tiene sus droguitas como todo hijo de vecino; luego le da por comprar pianos, como si los necesitara mucho, y luego no alcanzan las cuotas de los socios; y los señores de la junta que se empeñan en que la Sociedad no se acabe, y dan en que sería una lástima, y empeñan su crédito, y luego hasta dan conciertos y nos tienen arrobados una noche, por dos duros, para ver si pagan.

Pero esto sería largo y un poco feo para artículo de decreto, pero mi ministro me lo corregiría y saldría bueno. 
Artículo tercero... No; basta de artículos, porque saldría este más feo que el otro.

Por tanto mando, etc. -Benito Juárez.- Al C. Ministro, etc. ${ }^{20}$

En efecto, lejos de contentarse con un baño de legitimidad política, la Sociedad Filarmónica quería nada menos que una subvención y un edificio para impartir sus clases. Así que lo primero que hicieron los socios fue inscribir a Juárez como miembro de la misma. A tal efecto, una comisión formada por el Paganini mexicano acompañado de preciosas brujitas de Macbeth -pimpollos delicados de los jardines, falange vaporosa de serafines, les dijo uno de esos versitos que solían aventarse como confeti y que la prensa recogió- subió hasta el palco del presidente y le entregó un diploma que le acreditaba como miembro de la Sociedad. A la alumna Julia Espinosa de los Monteros le tocó la ingrata tarea de dirigir a don Benito el siguiente discurso:

Ciudadano presidente: Al tener el honor de poner en vuestras manos este diploma, en virtud de haberos dignado ser miembro de la Sociedad Filarmónica Mexicana, debemos haceros presente que el programa de esta asociación es difundir la educación artística, libre y gratuita entre los hijos del pueblo. La Sociedad Filarmónica ha hecho ya por nosotros esfuerzos importantes, y los seguirá haciendo porque nos quiere con un cariño entrañable, como a sus propios hijos; pero carece de los medios bastantes para proporcionarnos un local suficiente a las necesidades de su Conservatorio. En vuestras manos solo está cubrir este vacío del que depende la consolidación de un plantel que hará honor a México y proporcionará una carrera honrosa y lucrativa a millares de jóvenes, que como nosotros, tienen fijada en ella su porvenir. Dadnos un alojamiento competente,

${ }^{20}$ Facundo [José T. de Cuéllar], "Variedades. El concierto de anoche”, El Correo de México (2 oct. 1867), p. 2. 
la Universidad por ejemplo, y habréis hecho nuestra felicidad; -y nuestras bendiciones os seguirán siempre a por todas partes. ${ }^{21}$

Las crónicas nunca dijeron si el asunto de darle a la Sociedad Filarmónica un edificio ya iba planchado, o si la petición tomó a Juárez por sorpresa. Es de suponerse lo primero, porque en efecto, el Conservatorio de la Sociedad Filarmónica pudo mudarse al antiguo edificio de la Universidad en la calle de Corregidora -hoy inexistente-, donde se mantuvo por varias décadas.

Lo que no dijeron los cronistas, ni los historiadores o musicólogos que antes se han ocupado tanto de este concierto como de la pieza de Morales o de las tareas de la Sociedad Filarmónica Mexicana, es que al inundar aquel largo programa con piezas de ópera, no sólo se daba gusto a la rancia afición del público por ese género, sino que se buscaba dar a Juárez y a su gobierno una lección moral y política, una meliflua lectura de cartilla.

Desde las tempranas páginas de Historia Mexicana, el nombre de la Sociedad Filarmónica Mexicana y varias de las reseñas anteriormente citadas, ya se habían reproducido para contar algunos de los avatares de la Sociedad. ${ }^{22}$ Pareciera que reproducir los detalles del programa es sólo para dejar testimonio del gusto imperante, o de las modas musicales que soplaban en México en el otoño de 1867. Pero según hemos dicho, las fuentes documentales pueden oírse, pueden escucharse; más cuando el asunto que registran es, precisamente, de índole musical.

Y nada más fácil que escuchar ópera. Porque las diatribas lanzadas por Luis G. Ortiz contra los especialistas y su "tecnología

${ }^{21}$ El discurso fue anotado por Alfredo Bablot, "Gran concierto público de la Sociedad Filarmónica Mexicana”, El Monitor Republicano (4 oct. 1867), p. 2. ${ }^{22} \mathrm{El}$ programa entero del concierto fue reproducido y comentado por Cosío VILlegas, "Un viejo ariete musical”, pp. 302 y ss. 
difícil de entender" se originaron a raíz de la dificultad para explicar el sentido de la música instrumental, particularmente a partir del estreno de las grandes obras de Beethoven. ¿Cómo entender lo que ocurre al seno de las grandes piezas instrumentales sin recurrir al lenguaje técnico y, en particular, a la disección de los procesos armónicos que las sustentan? Pero con la ópera nunca hubo ese problema. El argumento y los textos cantados ya nos ofrecen los mínimos elementos para discernir el significado de lo que se canta, de lo que se escucha. Ello no quiere decir que no se pueda elaborar sobre los aspectos técnicos, internos, de la música; pero la ópera es mucho más democrática en su alcance y no se requiere gran bagaje técnico para poder entender y disfrutar los frutos de su amplio repertorio.

Una audición del programa que los filarmónicos ofrecieron a Juárez revela una conclusión inesperada. Porque lo menos que puede decirse es que los socios filarmónicos quisieron educar al presidente y que la elección de los números del programa, y en particular de los fragmentos de ópera incluidos, no fue de ninguna manera casual ni aleatoria. Su conjunto esboza un mensaje moral y político, pleno en alusiones a Dios y a su inapelable autoridad, tanto como ensalza las virtudes de los ciudadanos ejemplares y la gracia de aquellos gobernantes que saben ser magnánimos. Esa sub-trama llega tan lejos como para sugerir que, cuando los tiranos cobran venganza, la revolución y los alzamientos quedan justificados. Además, hace parecer que la Sociedad Filarmónica Mexicana ha sido como una joven, a la vez orgullosa y engañada, a la que sólo cabe ayudar.

¿Acaso desde la misma obertura de Emma d'Antiochia comenzaron las indirectas? Como la obertura utiliza una banda fuera de escena -la misma que Morales colocó sobre el escenario para su sinfonía-himno- pudiera tratarse de una coincidencia, y de una obra escogida en virtud de las fuerzas instrumentales ya disponibles En todo caso, sólo se tocó la obertura, pero cabe recordar que el libreto de Felice Romani es extraño porque, 
propiamente, no hay villanos en su trama. Lo que hay son viejos amores -entre la princesa Emma y Ruggiero, quienes ahora, casados con otras personas, no pueden reavivar su antiguo amor-. El final, sin embargo, será trágico: Ruggiero se va al exilio y Emma se administrará veneno a sí misma. ¿Acaso la república triunfante quería idéntica suerte para los infelices y otrora imperiales filarmónicos?

El Coro di Streghe al inicio del Macbeth de Verdi fue cantado, ya quedó dicho, no por siniestras brujas sino por pimpollos delicados de los jardines y, bien mirada, la idea de haber puesto a las niñas del Conservatorio a cantar ese coro maléfico sólo pudo ser de Lady Macbeth. En la archiconocida escena original, las brujas cantan acerca de sus terribles designios, y en el libreto utilizado por Verdi hablan de una pobre mujer a cuyo marido matarán en venganza. Es un coro difícil de cantar, y ningún programa nos dijo si lo cantaron completo -es decir, con la brillante segunda parte Le sorelle vagabonde /van per l'aria, van sull'onde- o sólo cantaron la primera estrofa. En cualquier caso, poner a las niñas a entonar los rencorosos versos - "Un huracán te proporcionaré..." "La tempestad levantaré..."-, era a todas luces un oxímoron destinado a mostrar que toda iracunda venganza era ridícula e infantil. Lo que las brujas cantaron a Juárez fue un gentil aviso: "nada de vendettas, por favor".

Los dos números de ópera siguientes fueron de Donizetti. Primero cantaron el terceto de Lucrezia Borgia, es decir, Guai se ti sfugge un moto, Se ti tradisce un detto!, el terrible y conmovedor final del primer acto, donde un gobernante malvado -Alfonso, duque de Este- envenena a Gennaro invitándole a beber una copa de vino que la propia Lucrezia debe verter. Mientras el duque Alfonso cree a Gennaro amante de Lucrezia, se trata en realidad del hijo de ésta, de modo que la tensión alcanza su máxima intensidad cuando asistimos al envenenamiento del hijo a manos de su propia madre. Con desprecio, el Duque los deja solos, pero Lucrezia conseguirá que Gennaro beba el antídoto. 
La escena y el acto culminan con una espectacular cabaletta: Lucrezia celebra la salvación de su hijo mientras Gennaro le advierte: “ $i Q u e$ te castigue, si es una traición, quien más esperes que se apiade de ti!” Esperemos que Juárez no haya entendido nada y que sólo se haya dejado llevar por la emocionante música de tan famosa escena.

Pero vino una pieza y una palada nueva, como diría José Tomás de Cuéllar. O al menos eso cabe suponer, ya que todo lo que el programa consignó fue que se interpretó una "Invocación vespertina" de Donizetti. Como hubo de ser un trozo para voces masculinas, puesto que fue cantado por el orfeón dirigido por Ituarte, y por las circunstancias políticas que definieron el programa y su contenido, mi apuesta es que se trató de $O$ sacre polve, de la ópera L'Assedio di Calais. La letra es muy parecida a la utilizada por Morales y alude a la patria y al suelo natal. Es el canto de unos ciudadanos dispuestos a sacrificarse, por su tierra, por su patria, ante las terribles exigencias del vencedor rey de Inglaterra; aunque al final de la ópera el sacrificio y valentía de los ciudadanos tocarán el magnánimo corazón del monarca, que habrá de perdonarlos. Ciudadanos ejemplares, gobernantes magnánimos, amores pasados y hoy imposibles, venganzas ridículas... ¿ Hay algo que aún no quede claro, señor presidente?

A la luz de las anteriores piezas, la elección del coro y vals de Faust resulta paradójica. Lo primero que habrán pensado en interpretar los músicos de la Sociedad Filarmónica habrá sido el famoso coro de los soldados, Déposons les armes, cuyo texto insufla los ánimos patrios y exalta el abandono de las armas tras el combate por la patria. Como además es para voces masculinas y posee una música marcial muy fácil de escuchar, esa tuvo que ser la primera elección. En su lugar, se interpretó la escena del final del segundo acto, cuando Mefistófeles y Fausto encuentran a Margarita y ésta rehúsa los avances del joven sin alma: 
¡No, señor! Ni soy señorita, ni bella, iy no necesito que me ofrezcan el brazo. ${ }^{23}$

¿Eran esos los orgullosos versos que los filarmónicos querían hacer escuchar a Juárez? Apenas una escena antes, Mefistófeles ha sido rechazado mediante la señal de la cruz que dos espadas han formado, y por tanto hay al centro de este punto dramático una clara ponderación de la virtud, y del triunfo del bien sobre el mal. Por lo demás, ese breve intercambio de palabras entre los protagonistas queda inmerso en el famoso coro donde, al incesante vuelo de un vals, todos cantan con exaltación:

ique el vals nos arrastre!

¡Haced retumbar la llanura

con el estallido de vuestras canciones!

El claroscuro que dibujan los horrores de las guerras, por un lado; y las delicias de la paz por el otro, fue una experiencia común a las sociedades burguesas del siglo xix. De ahí que en tiempos de paz fuera patente un auge de los bailes, forma favorita de convivencia social que inundó la vida de aquella centuria. Ese vals de Fausto no es entonces un número más, aunque se trata de música muy conocida y ampliamente gustada, sino que debe leerse como una declaración pública; como la declaración de principios de una sociedad que se dispone a dejar atrás los desastres para vivir, en adelante, armoniosamente. Hoy, alejados de todo aquello y acostumbrados a escuchar la ópera bajo un curioso barniz de elitismo y elevación, quizá la música de baile nos pueda parecer superficial y un tanto ligera; para los decimonónicos, en cambio, aquel coro de Fausto revelaba, mejor

${ }^{23}$ Non monsieur! je ne suis demoiselle, ni belle, / Et je n'ai pas besoin qu'on me donne la main! 
que nada, los afanes de paz y convivencia que se deseaban de cara al futuro inmediato. Si un país, si una sociedad, cambiaban el teatro de la guerra por el Teatro Nacional -como había hecho el ejemplar ciudadano Feliciano Chavarría-, entonces la patria estaría salvada. Y por esta razón la pieza siguiente fue, precisamente, una oración, la sinfonía himno de Morales cuyo lugar emblemático en el programa se marcó con un claro cambio de escena: "Después de esta pieza [Faust], se bajará el telón, y volverá a alzarse de nuevo para la ejecución de la sinfonía-himno".

Para la segunda parte del gran concierto hubo más de lo mismo y ¡más Donizetti! La trama de Poliuto volvió a poner sobre la escena temas cruciales para los filarmónicos: la religión, el poder y el convencimiento irrenunciable de la fe adoptada. Paulina y Poliuto, los protagonistas, son víctimas cristianas de los conquistadores romanos. Severo -jSevero!- es el nuevo gobernante de Armenia y ha condenado a todos los cristianos a morir. Aunque en el pasado Paulina y Severo fueron amantes, la protagonista decide seguir al cadalso a su inamovible esposo. En el famoso dueto cantado esa noche $-A b$ ! fuggi da norte orribil cotanto-, Paulina pide a Poliuto ser bautizada y éste duda y se conmueve: “¡Un horrible frío invade mi corazón!” El destino, sin embargo, es inexorable y Paulina ya escucha el canto de las

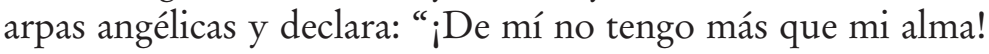
¡Ya estoy a los pies de Dios!” Al final, ambos cantan embelesados bajo el influjo de su fe: vivirán eternamente en el cielo libertador, aunque el régimen en turno los arroje a las bestias del circo.

Con el famoso cuarteto de Rigoletto - "Bella hija del amor..."el programa diseñado por la Sociedad alcanzó tal vez su momento más delicado. El Duque de Mantua representaba al déspota por antonomasia; a un hombre poderoso capaz de cualquier cosa. Además, el personaje había salido de la pluma de Víctor Hugo, lo que a Juárez quizá le habría resultado incómodo. Pero tal vez no lo supo porque ya Verdi había tenido que lidiar con la 
censura austríaca para poder representar la ópera, lo que le llevó a cambiar los nombres originales y a situar la horrorosa trama en un extinto ducado de Mantua. En todo caso, el famoso fragmento seleccionado es una escena desgarradora: mientras el Duque seduce a Magdalena, Gilda escucha y se desengaña: las mismas palabras lisonjeras que el Duque le dijo para seducirla son ahora empleadas para conseguir el favor de un nuevo amorío. Gilda canta conmocionada:

Esas mismas palabras de amor...

¡el infame, me las dijo a mí!

Infeliz corazón engañado,

no te rompas de dolor...

En suma, el cuarteto de Rigoletto reúne dos filones argumentales del programa: el despreciable abuso del poder que distingue a los malos gobernantes con el arrepentimiento de una pobre hija del amor; es decir, de una Sociedad Filarmónica a la que ese infame habló con palabras de amor. “¿Por qué, corazón crédulo [se pregunta Gilda] amas a un hombre de esta clase?” Así las cosas, la Sociedad Filarmónica Mexicana, que en la primera parte había sido la orgullosa Margarita, encarnaba en una inocente Gilda a quien cierto infame de apellido austríaco había seducido.

Se habían confesado las culpas. Se había exaltado la inamovible fuerza de la fe, se había ridiculizado a los gobernantes tiranos y exaltado a los magnánimos. Se había, también, halagado al gobierno con las marchas de Aniceto Ortega y se había pedido a Dios por el salvamento de la patria. Cumplido su propósito edificante, la Sociedad sólo requería un último número para cerrar aquel largo y sinuoso programa, y para ello se escogió un fragmento de otra famosa ópera francesa, La Muette de Portici, de Auber. La música-festiva, esperanzadora, impregnada de optimismo- era idónea para un lieto fine 
pero no había por qué contentarse con ello, así que se aprovechó la ocasión para dar un último consejo: cuando se gobierna en contra del pueblo, cuando se gobierna contra las buenas causas, los levantamientos no tardan en venir. De hecho, el estreno de la ópera en agosto de 1830 en el Théâtre de la Monnaie en Bruselas -y en particular el aria de Masaniello, Amour sacré de la patrie-suele asociarse a la revolución que expulsó a los holandeses de Bélgica. De nueva cuenta, resulta muy difícil no establecer un paralelismo entre Fenella, la protagonista de la ópera, y la Sociedad Filarmónica. Para empezar, se trata de una heroína muda, que no canta y que es una fugitiva. En la escena del tercer acto, interpretada para cerrar el concierto, un oficial al servicio del virrey descubre a Fenella e intenta apresarla: ésa será la señal para que el pueblo, reunido en el mercado de Portici, se levante contra la opresión. Las mujeres serán las primeras en alzar sus voces:

\section{¡Oh, cielos! ¡ La inocente cautiva! \\ Quieren llevarla prisionera \\ ¿Qué habrá becho?}

Antes de finalizar la escena con un coro general, Masaniello y el coro cantan otra plegaria más:

Santo bendito, cuya divina imagen protege las cunas de nuestros niños. iTú que nos das la fuerza y el coraje, tú que consuelas a los pobres en sus trabajos, tú que nos ves postrados a tus pies! ¡Quédate con nosotros, protégenos!

Cantada la oración, la triunfal música de Auber acompañará al pueblo a la revuelta, provisto ya de armas y antorchas: si el gobierno quiere encerrar a la joven muda, las consecuencias 
serán terribles y, al menos a los ojos de los filarmónicos, México seguirá entonces la misma suerte que Nápoles: habrá revoluciones que tendrán de fondo la incontenible erupción del VesuvioPopocatépetl.

Lo que ni los historiadores ni las fuentes dicen es qué tanto entendía Juárez de ópera. Pero la reiterada cita de cierto episodio lírico denota que al menos los rasgos fundamentales de los argumentos de las óperas eran conocidos, entendidos y trasladados a la vida cotidiana. La historia en cuestión ha sido repetida con insistencia porque se juntan en ella dos amores comunes -el de la patria liberal y el de la diva mexicana Ángela Peralta-. De acuerdo a la narración de Sebastián I. Campos en sus Recuerdos históricos, ya desde enero de 1867 la música de Bellini, en voz de la diva mexicana, había servido para llamar al alzamiento en pro de la patria:

Su presentación en el palco escénico fue el principio de una ovación no interrumpida, que llegó a su colmo cuando en la última parte del programa, el dúo de las banderas de la ópera I Puritani, Ángela, arrancando de las manos de la artista que la acompañaba la bandera mexicana, que al efecto se había colocado en el escenario, la tremoló ardientemente, lanzando la última frase: gridando libertá, con tan poderosa voz, con acento tal de patriotismo y de entusiasmo, que los gritos de “¡Viva México”! con que las respondieron, llegaron al frenesí.

Entonces tuvo lugar lo inesperado. Un grito sonoro, formidable; un grito de dolor, de rabia, un grito que sobrepujó a los demás, que se hizo oír sobre todos, partiendo de la galería se impuso y provocó la tempestad.

-¡No!-rugió el valiente y desconocido espectador-¡No! ¡Abajo el imperio! ¡Viva Juárez! ¡Viva la república! 
Y aquel grito, contaminando, electrizando a la concurrencia, se repitió por centenares de bocas, que tenían sed de vitorear a la patria y saludarla con su verdadero nombre. ${ }^{24}$

No es éste el espacio para leer entre líneas este episodio de la vida de Ángela Peralta, sino para regresar al tema inicial: las fuentes históricas, cuando hablan de música, ameritan ser escuchadas pues de lo contrario pudieran cometerse algunas desafinaciones. Así han hecho quienes han citado este pasaje de los Recuerdos ${ }^{25}$ para exaltar a la Peralta. El problema, como sabrán los dilettanti adeptos a Bellini, es que el famoso dúo de I Puritani no es para voces femeninas, sino masculinas. ¿Cantó la Peralta un trozo de Bellini que no era para soprano? Eso es tanto como pedir un vaso de agua en una bodega de vinos de Borgoña; algo posible, pero difícil de creer y mucho peor de oír. En todo caso, es curioso que otro biógrafo de Juárez haya contado prácticamente la misma historia, con la imprescindible música de Bellini como trasfondo, sólo que ahora sin sopranos usurpadoras:

En la noche del 23 de diciembre se encontraba Juárez con su familia en el Teatro Principal de Veracruz, ocupando el palco del centro; en el de su derecha estaba Gutiérrez Zamora y puede decirse que toda

24 Campos, Recuerdos históricos, p. 487.

25 Al parecer, la anécdota ha regado una cauda historiográfica de citas curiosas. Jesús C. Romero parece haber sido el primero en ocuparse del asunto, pero fue Esperanza Pulido, en su libro La mujer mexicana en la música, quien le dio fama y vuelo a la historia: "la Peralta demostró más tarde un ardoroso patriotismo. El Dr. Romero describe, como sigue, lo sucedido en Veracruz el 6 de enero de 1867, durante una función de la Compañía de Ópera de la cantante...”. Pulido no citó los datos de las páginas que estaba leyendo de Romero (probablemente algún artículo de la revista Carnet Musical), así que autores posteriores citaron a Pulido como fuente de la historia. Sólo Ingrid Bivián (“El canto del 'Ruiseñor””), ofreció la fuente original de la historia, aunque dejó pasar de largo los problemáticos detalles técnicos que enseguida se mencionan. 
la sociedad veracruzana se había dado cita en aquel lugar, donde una excelente compañía de ópera cantaba esa noche I Puritani.

Justamente en los momentos en que el público aplaudía con entusiasmo el popular "Dúo de las banderas”, llegó apresuradamente al palco del Presidente un hombre cubierto de polvo, vestido de charro y que parecía venir de camino. Era un correo extraordinario; se llamaba José María Machuca, natural de Tehuacán, quien en veintiocho horas había recorrido las trescientas millas, poco más o menos, de mal camino, que mediaban entre el cuartel general de González Ortega y el puerto de Veracruz. Este correo entregó un pliego al presidente.

La función quedó interrumpida por la entrada violenta de aquel hombre. El público, los cantantes y la orquesta guardaron un silencio profundo y lleno de ansiedad. ¿Qué pasaba? ¿Qué significaba aquello? ¿Era noticia próspera o adversa? Nadie lo sabía; pero todos presentían algo de muchísima importancia.

Juárez, que se había puesto en pie para recibir al correo, abrió el pliego, leyó tranquilamente las pocas líneas que contenía; después se acercó a la barandilla del palco. El público, anhelante, se puso también en pie, guardando el silencio profundo de la ansiedad. Juárez, con voz pausada y ligeramente conmovida, leyó la comunicación en que se le participaba la completa derrota de Miramón en Calpulalpan, y que inmediatamente ocuparía la capital el ejército de la Reforma.

Lo que pasó después no puede ser descrito. Juárez y Gutiérrez Zamora se dieron un estrecho abrazo. Resonó un formidable ¡Viva! que encontró inmediato eco en toda la ciudad. La orquesta tocó diana, los cantantes quisieron entonar La Marsellesa, pero el público, en el delirio del entusiasmo, no atendía a nada que no fuese Juárez, que fuese Zamora, su glorioso colaborador [...] Las bandas de los cuerpos de la guarnición se echaron a [...] cantar en formidable coro la canción de Los cangrejos; que fue nuestro himno de guerra en esa cruenta campaña $[\ldots] .{ }^{26}$

26 Zayas Enríquez, Benito Juárez, su vida-su obra, pp. 105-106. 
También es probable, para no dudar más de los testimonios citados, que las dos historias hayan sido verídicas y que, en efecto, la misma música de Bellini acompañase las guerras liberales tanto en 1860 como en 1867. En cualquier caso, lo fidedigno de las anécdotas es para nuestro propósito un asunto secundario. Lo importante radica en que tales historias implican un entendimiento dramático y argumental de la ópera; una visión del género que, desde luego, hoy no es la nuestra. Acostumbrados a una calidad musical sin precedentes $y$, en tiempos recientes, a producciones teatrales plenas en recursos, las historias y los textos de las óperas ocupan para nosotros un injusto segundo plano. Para los decimonónicos, en cambio, la ópera era portadora de significados y argumentos, de situaciones extremas, de dilemas morales y éticos que estaban a la par o incluso por encima de la propia música. Es por ello que la ópera, creían los filarmónicos, era la que podía salvar a la patria.

En cualquier caso, los alcances históricos de aquel concierto extraordinario de octubre de 1867 siguen vigentes: Juárez otorgó a los filarmónicos el edificio que tanto anhelaban (el viejo edificio de la Universidad, hoy derruido) y diez años después, en 1877 y a raíz del estipendio gubernamental del que gozaba, el Conservatorio de la Sociedad Filarmónica se convirtió en el Conservatorio Nacional. Si el gesto magnánimo se debió a las lecciones de ópera que los filarmónicos dieron al presidente aquella noche, habrá que reconocerle un acto de tolerancia y visión de Estado. Pero si Juárez salió del teatro sin haber entendido el trasfondo político y moral que ahí se le había planteado, todavía mejor. Porque de haber intuido que en algún momento se le comparaba con el Duque de Mantua, con Severo, o peor aún, con el mismísimo Mefistófeles; entonces quizá el conservatorio y sus filarmónicos seguirían deambulando por ahí.

En cambio, los ecos estéticos parecen cada vez más débiles. Ya nadie escucha a Mercadante; y la revolución del mercado en La Muda de Portici sólo será el feliz reducto de algunos 
cuántos. Por no hablar del olvidado Melesio Morales y su sinfonía-himno cuyas notas dieron solemne voz a las aspiraciones sociales de quienes abarrotaron el Teatro Nacional en 1867. Pero acaso contar la densa historia detrás de aquel estreno sirva para justipreciar, en términos estéticos e históricos, la importancia y trascendencia de las notas que guardan aquellas pautas, por igual guerreras y patriotas. Conmueve atestiguar que los mexicanos de entonces creían en el poder ético de la música y que, fieles a ello, les parecía bastante interpretar un selecto programa para que la salvación de la patria cobrara sus primeros visos de certeza. Y puesto que nada parece haber funcionado, quizá no sea desmesurado volver a intentarlo y llamar al rescate a las brujitas de Macbeth, a los niños de Morales, a los mercaderes de Portici y a todos los demás personajes que cantaron aquella función irrepetible destinada a salvarlo todo: a Morales, a su familia, a la Sociedad Filarmónica Mexicana y, de paso, a la patria entera.

\section{SIGLAS Y REFERENCIAS}

FR-CNM Fondo Reservado, Biblioteca Candelario Huízar, Conservatorio Nacional de Música, Ciudad de México, México.

Barceló, Alejandro, Israel Cruz Olalde, Armando Gómez Rivas y Ramón Romo LizÁrRaga, 150 años de educación musical en México, México, Instituto Nacional de Bellas Artes, 2006.

Bellinghausen, Karl, "Esbozo biográfico de Melesio Morales”, en MoraLES, 1999, pp. ix-xlix.

Bivián, Ingrid, “El canto del 'Ruiseñor': un acercamiento a la creación del mito de Ángela Peralta (1860-1866)”, en SuÁrez DE LA Torre (coord.), 2014.

Campos, Sebastián I., Recuerdos históricos de la ciudad de Veracruz y costa de Sotavento, México, Oficina Tipográfica de la Secretaría de Fomento, 1895.

Cosío Villegas, Emma, “Un viejo ariete musical”, Historia Mexicana, I: 2 (2) (oct.-dic. 1951), pp. 302-310. 
Gómez Rivas, Armando, "El pasaporte musical del Conservatorio: MéxicoParís via Florencia (1866-1910)”, en Barceló, Cruz Olalde, Gómez Rivas y Romo LizÁrraga, 2006, pp. 37-77.

Morales, Melesio, Dio salvi la patria, manuscrito y partes de la obra, México, Fondo Reservado, Biblioteca Candelario Huízar, Conservatorio Nacional de Música, FR-CNM, núm. 2168/104/2288-9.

Morales, Melesio, Mi libro verde de apuntes e impresiones, introducción de Karl Bellinghausen, México, Conaculta, 1999.

Morales, Melesio, Labor periodística, selección, introducción, notas y hemerografía de Áurea Maya, México, Centro Nacional de Investigación, Documentación e Investigación Musical, 1994.

Pulido, Esperanza, La mujer mexicana en la música, México, Ediciones de la Revista Bellas Artes, 1958.

SUÁrez DE LA TORRE, Laura (coord.), Los papeles para Euterpe. La música en la cindad de México desde la bistoria cultural. Siglo XIX, México, Instituto de Investigaciones Dr. José María Luis Mora, 2014.

Zayas Enríquez, Rafael de, Benito Juárez, su vida-su obra, México, tipografía de la Viuda de Francisco Díaz de León, 1906. 